\title{
Instructors' Ideas about Problem Solving - Grading
}

\author{
Vince H. Kuo*, Kenneth Heller ${ }^{*}$, Patricia Heller ${ }^{*}$, Charles Henderson*, Edit Yerushalmi ${ }^{* \xi}$ \\ *Physics Education Research Group, University of Minnesota, Minneapolis, MN \\ ${ }^{\xi}$ Weizmann Institute, Rehovot, Israel
}

\begin{abstract}
The Physics Education Research Group at the University of Minnesota has developed an interview tool to investigate physics faculty views about the learning and teaching of problem solving. In the part of the interview dealing with grading, faculty members were asked to evaluate a set of five student solutions and explain their reasons for the grades that they assigned. Preliminary analysis on two of the five student solutions was done on six physics faculty members from a large research university. The results seem to indicate that faculty members hold conflicting beliefs when grading: between valuing reasoning in student solutions and wanting to give students the benefit of the doubt. This paper will illustrate the hypothesis that physics faculty hold conflicting values when grading, and describe how the research university faculty resolved their conflicts.
\end{abstract}

\section{Introduction}

Many studies have found that introductory physics students come out of traditional physics classes able to solve test problems without understanding the physics concepts on which the problems are based ${ }^{1}$. This suggests that either the problems posed for students are inadequate, or the process by which they solve them is not the intended one. Curriculum developers have focused their efforts on two general ways of attacking this problem. Some emphasize directly building students' conceptual knowledge ${ }^{2,3,4}$, while others emphasize developing student problem-solving skills ${ }^{5-11}$. Although aspects of many of these curricula are reflected in faculty practices, seldom are they fully adopted. It is our belief that this lack of full adoption reflects a mismatch between the curriculum developers who design the instruction and the faculty for whom the instruction is designed.

In order to understand the nature of this mismatch, we conducted interviews with 30 physics faculty members to determine their beliefs and values. The purpose of this study is to generate a set of testable hypotheses on a common core of physics faculty values and beliefs about the teaching and learning of problem solving. The preliminary results from this study will serve as guidelines for further investigations on larger samples.
This is the first in a series of three papers describing the study and its preliminary results, and will concentrate on the findings in regards to grading of student solutions. Grading is an important part of the curriculum since, in the student's view, it communicates the expectations of the instructor. This paper will identify some values that physics faculty hold when they evaluate and interpret student performances from their problem solutions. The following two papers will discuss preliminary results from a detailed analysis of the six research university faculty members that we interviewed to determine: (1) their beliefs about student learning of problem solving in physics $^{12}$; and (2) relationships between the faculty's beliefs about student learning and their expectations for their students ${ }^{13}$.

\section{Interview}

The interview was based on the use of instructional artifacts ${ }^{14}$ in physics instruction. All of the artifacts below dealt with the same physics problem given to the faculty to solve prior to the interview (see Figure 1). The artifacts used were:

1. three instructor solutions that varied in the details of their explanation, physics approach, and presentation structure;

2. five student solutions that were selected from actual final examination solutions at the University of Minnesota to 


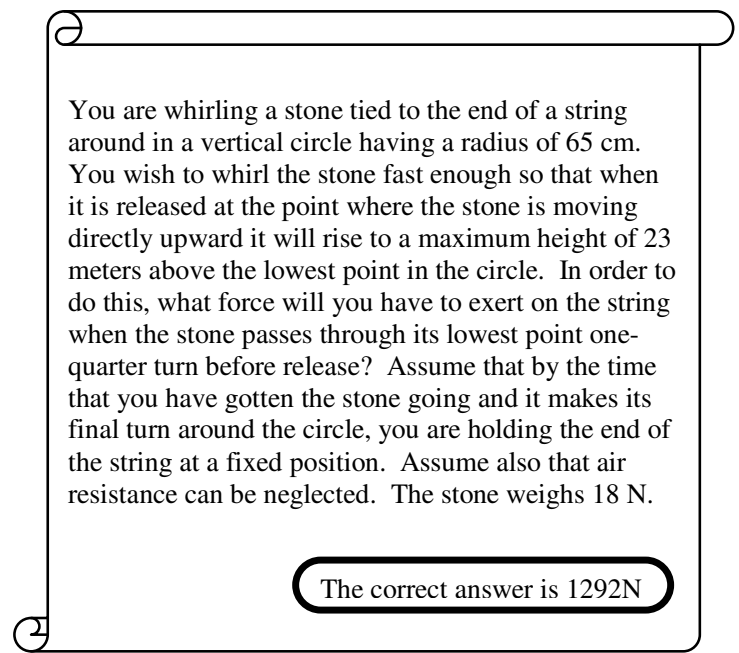

Figure 1: Homework Problem.

represent features of student practice, such as evidence of varying degrees of conceptual knowledge, knowledge organization, and organization of a decision-making process; and

3. four problems types that represent a range of the types of problems used in introductory physics courses.

Each individual interview with a faculty member lasted about $1 \frac{1}{2}$ hours and consisted of four parts. The first three parts of the interview, each dealing with one of the three artifacts, started with general questions about how and why the faculty used that type of artifact. The faculty interviewed was asked to compare each artifact to those he or she actually used. We concluded each part by asking the faculty to reflect on the problem-solving process, as represented in the artifacts. During these three parts the interviewer noted each of the features of the problem-solving process that was mentioned on a separate index card, using the faculty member's words. In the final part of the interview they were asked to sort these cards into categories of their choosing. They were then asked several questions about the categories, including their expectations about student learning of these problemsolving processes by the end of their course.

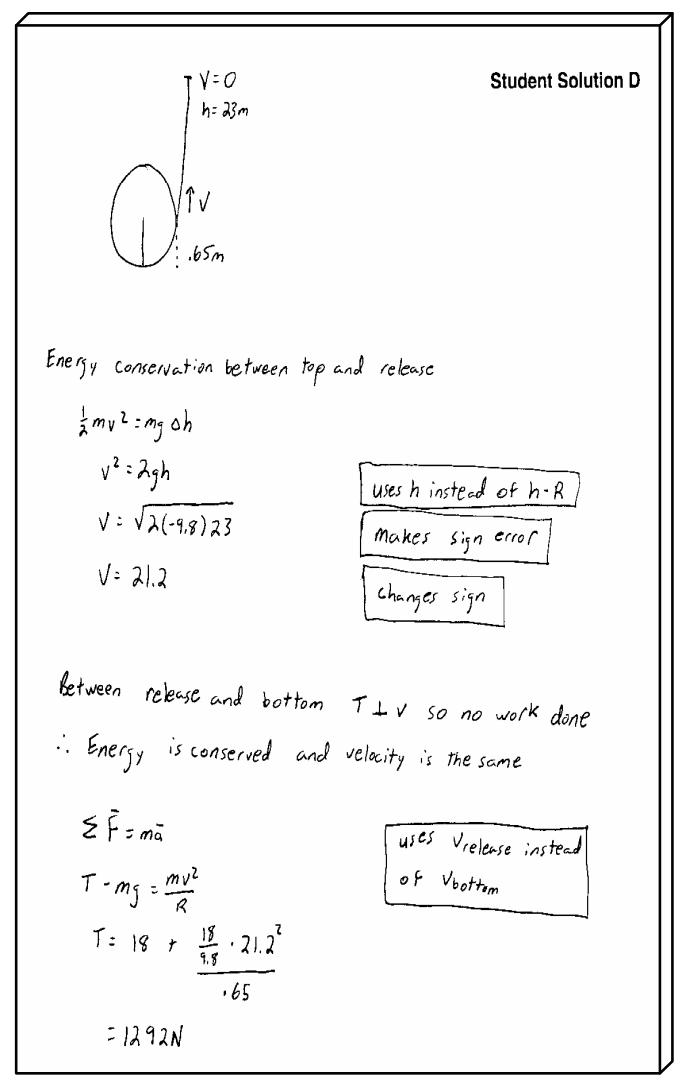

Figure 2: Student Solution D (SSD). The boxed-off comments were written by the interviewers to indicate clearly identifiable mistakes so as to save time during the interview.

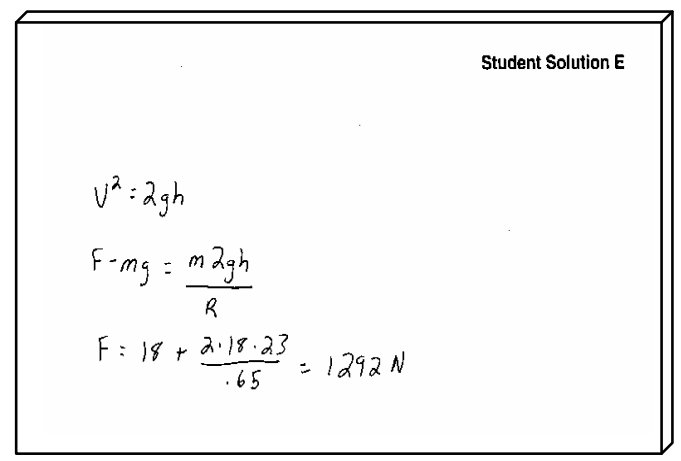

Figure 3: Student Solution E (SSE).

The 30 faculty members interviewed were randomly chosen from a set of physics faculty located in Minnesota who had taught an introductory calculus-based physics course within the previous 5 years and could be visited and interviewed in a single day (107 possible; 35 contacted; 5 declined to 


\begin{tabular}{|c|c|c|c|c|c|c|c|}
\hline \multirow{2}{*}{\multicolumn{2}{|c|}{ Values }} & \multicolumn{6}{|c|}{ Faculty } \\
\hline & & 1 & 2 & 3 & 4 & 5 & 6 \\
\hline \multicolumn{2}{|c|}{$\begin{array}{l}\text { 1. Instructors want to see reasoning in student solutions so they can } \\
\text { know if a student really understands. }\end{array}$} & \multirow[t]{3}{*}{$\sqrt{ }$} & & $\sqrt{ }$ & $\sqrt{ }$ & $\sqrt{ }$ & $\sqrt{ }$ \\
\hline \multirow{2}{*}{$\begin{array}{l}\text { 2. Instructors are reluctant to } \\
\text { penalize a student who } \\
\text { might be correct: }\end{array}$} & \multirow{2}{*}{$\begin{array}{l}\text { - Burden of proof on the instructor; } \\
\text { - View student solutions in best } \\
\text { possible light. }\end{array}$} & & & $\sqrt{ }$ & & $\sqrt{ }$ & $\sqrt{ }$ \\
\hline & & & $\sqrt{ }$ & $\sqrt{ }$ & $\sqrt{ }$ & $\sqrt{ }$ & $\sqrt{ }$ \\
\hline \multirow{2}{*}{$\begin{array}{l}\text { 3. Conflict Resolution for } \\
\text { SSE: }\end{array}$} & \multirow{2}{*}{$\begin{array}{l}\text { - Insist on reasoning; } \\
\text { - Compromise; } \\
\text { - Give full credit. }\end{array}$} & 4 & \multirow{2}{*}{$\begin{array}{l}\mathbf{N} \\
\mathbf{A}\end{array}$} & & \multirow{2}{*}{7} & & \\
\hline & & & & 9 & & 10 & 9 \\
\hline
\end{tabular}

Table 1: Conflicting Values and Resolutions - note that the $\sqrt{ }$ 's indicate the faculty holding that particular value, and the numbers are the grades that they assigned for SSE. Merged cells indicate a slight leaning of the faculty in that direction of the resolution.

participate). The 30 participants were roughly divided equally among four types of higher education institutions: Community College (CC), State College (SC), Private College (PC), and Research University (RU).

\section{Grading}

The remainder of this paper will focus on the Student Solutions part of the interview. The faculty members were asked to grade five student solution artifacts on a ten-point scale. They were then asked to discuss the problem-solving knowledge or skills represented in each solution, and explain the reasons for their grading.

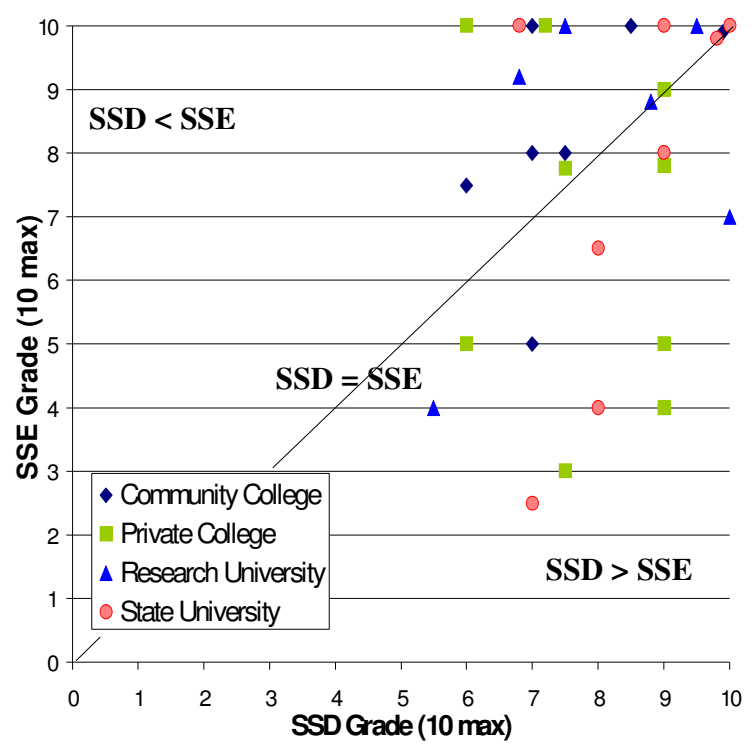

Graph 1: Grade Comparison between SSD and SSE.
The results presented in this paper are a comparison between two of the five student solutions, Student Solution D (SSD) and Student Solution E (SSE), shown in Figures 2 and 3. SSD is a detailed solution, with explanations and reasons for the problemsolving process written in the solution. It has two mistakes that combine to yield the correct numerical result. SSE also has the correct numerical answer, but has no explanations. Notice that SSE could have been using the same reasoning as SSD.

A preliminary analysis compared the numerical grade that all thirty of the faculty members assigned to SSD and SSE. Graph 1 indicates that the distribution was roughly evenly divided between those who gave SSD a higher grade (SSD > SSE) and those who gave SSE a higher grade (SSD < SSE), with a few that graded them both equally $(\mathrm{SSD}=\mathrm{SSE})$. The scoring of each solution differed vastly among individual faculty, especially on the grading of SSE. Only the community college faculty showed a noticeable bias toward one solution, preferring SSE.

In order to understand these differences in grading, and to generate some hypotheses, we looked more closely at the interview transcripts of the six research university faculty, particularly the parts of the interviews that dealt with SSD and SSE. 
During the interview five out of the six research university faculty expressed conflicting values when grading SSE (see Table 1). Although these five faculty members stated that they valued reasoning in the student solution, only one actually graded accordingly. The rest of the faculty were reluctant to penalize a student who might have the correct understanding. Faculty \#6, while commenting on SSE, stated that, "there's nothing really wrong with this. You'd have to question, though, whether or not he was thinking of the fact that energy is conserved as it's on the string as well as when it's flying. He didn't show that he's using the right principles (9 points)." Judging from this statement, and others like it, we can hypothesize that some of the faculty felt that the burden of proof fell on them to prove that the student did not understand the physics.

Other faculty members felt that they should always view the student solution in the best possible light. For example, Faculty \#3 commented, also about SSE, that, "the student fundamentally knows what's going on (9 points)." The seemingly conflicting values of desiring explanation but wanting to give student the "benefit of the doubt" were resolved by the faculty mostly through assessing minor penalties (1 to 3 points out of 10) to SSE, and stating that they would include a comment conveying to the student that, "next time you should really show your reasoning."

\section{Discussion}

The preliminary analysis of the grading part of the interview yielded a possible source of conflict within physics faculty teaching introductory physics. Based on this small sample, it appears that physics professors value seeing student reasoning in problem solutions, yet actually penalize this behavior in students. We intend to test this hypothesis by examining the values expressed in the other 24 faculty interviews. If the conflict between values and grading remains, a further study is also planned using tools suitable for a significantly larger sample.

\footnotetext{
${ }^{1}$ Maloney, D., Research on problem solving: Physics, in D, Gabel (ed.), Handbook of Research on Science Teaching and Learning, MacMillan, New York, 1994. ${ }^{2}$ Laws, P.W., Millikan Lecture 1996: Promoting active learning based on physics education research in introductory physics courses, American Journal of Physics, vol. 65, pp. 14-21, 1997.

${ }^{3}$ McDermott, L.C., Shaffer, P.S., \& the Physics Education Group, Tutorials in Introductory Physics Preliminary Edition, Prentice Hall, Upper Saddle River, NJ, 1998.

${ }^{4}$ Mazur, E., Peer Instruction: A User's Manual, Harvard University, 1992.

${ }^{5}$ Reif, F., \& Scott, L., Teaching scientific thinking skills: Students and computers coaching each other, American Journal of Physics, vol. 67, pp. 819-831, 1999.

${ }^{6}$ Heller, P., Keith, R., \& Anderson, S., Teaching problem solving through cooperative grouping. Part 1: Groups versus individual problem solving, American Journal of Physics, vol. 60, pp. 627-636, 1992.

${ }^{7}$ Heller, P., \& Hollbaugh, M., Teaching problem solving through cooperative grouping. Part 2: Designing problems and structuring groups, American Journal of Physics, vol. 60, pp. 637-645, 1992.

${ }^{8}$ Mestre, J., Dufresne, R., Gerace, W., \& Hardiman, P., Promoting skilled problem-solving behavior among beginning physics students, Journal of Research in Science Teaching, vol. 30, pp. 303-317, 1993.

${ }^{9}$ Van Heuvelen, A., Learning to think like a physicist: A review of research-based instructional strategies, American Journal of Physics, vol. 59, pp. 891-897, 1991.

${ }^{10}$ Reif, E., Millikan Lecture 1994: Understanding and teaching important scientific thought processes, American Journal of Physics, vol. 63, pp. 17-32, 1995. ${ }^{11}$ Leonard, W., Dufresne, R., \& Mestre, J., Using qualitative problem-solving strategies to highlight the role of conceptual knowledge in solving problems, American Journal of Physics, vol. 64, pp. 1495-1503, 1996.

${ }^{12}$ Heller, P., Heller, K., Henderson, C., Kuo, V.H., \& Yerushalmi, E., Instructors' beliefs and values about learning problem solving, Proceedings of the Physics Education Research Conference, Rochester, NY, July, 2001.

${ }^{13}$ Henderson, C., Heller, K., Heller, P., Kuo, V.H., \& Yerushalmi, E., Instructors' ideas about problem solving - setting goals, Proceedings of the Physics Education Research Conference, Rochester, NY, July, 2001. ${ }^{14}$ Yerushalmi, E., Heller, K., Heller, P., Henderson, C., \& Kuo, V.H., Why solve problems? - Interviewing college faculty about the learning and teaching of problem solving, Proceedings of Physics Teacher Education Beyond 2000 International Conference, Barcelona, Spain, August, 2000.
} 